\title{
Sugar-touting nanny arrested for child abuse
}

A children's nanny was arrested this week and charged with ruining the teeth of two minors in her care.

The nanny has been employed by a family residing in the borough of Kensington and Chelsea since September last year, in which time she is said to have caused the destruction of the dentition of a boy aged six and a girl aged eight. At a recent dental appointment, both children were diagnosed with gross caries and referred for multiple extractions under general anaesthetic.

It is reported that the children had an unblemished dental record prior to the employment of their current nanny. Their father, who works in finance in the City, said: 'My children have always had a healthy diet and sweets are an occasional treat. We have endeavoured to instil the importance of tooth brushing twice a day in our children from an early age, and our nannies are well aware of this'.

The onset of the children's rampant decay is said to have been triggered by the nanny's insistence that they consume a spoonful of sugar with their daily vitamin medicine, to 'help it go down'. The children's mother discovered a large bowl of sugar and a teaspoon in the children's nursery, in an easily accessible position,

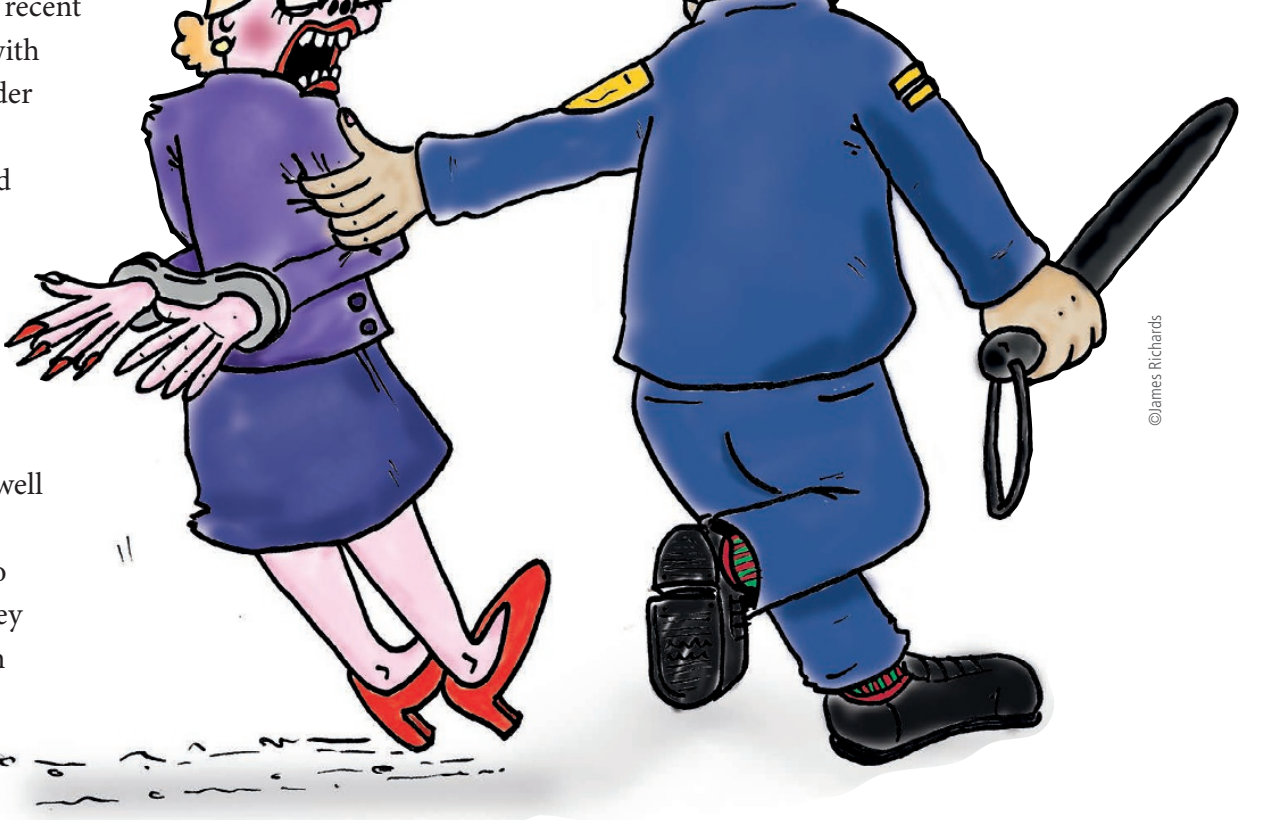
and $1 \mathrm{~kg}$ bags of refined white sugar in the nursery cupboard, next to the toys. It is thought that the children developed a taste for the spoonfuls of sugar and were helping themselves on a regular basis, both before and after tooth brushing.

It is not known whether other children suffered the same fate in the care of the accused nanny, as she was employed in her current post on the basis of her 'winning smile, captivating charm and exquisite singing voice' - according to the present victims' parents - as well as her impressive apparent ability to discipline and control young, spirited children.

\section{Fluoridated single malt to hit supermarket shelves}

Luxury goods producers have rushed to modify tooth-unfriendly products in the run up to Christmas after the media knocked the fizz out of Prosecco earlier this year.

In the summer the nation was shaken by the idea that Prosecco (the sparkling, often sweet alcoholic beverage made from Glera grapes) was bad for your teeth. Prosecco producers leapt to the

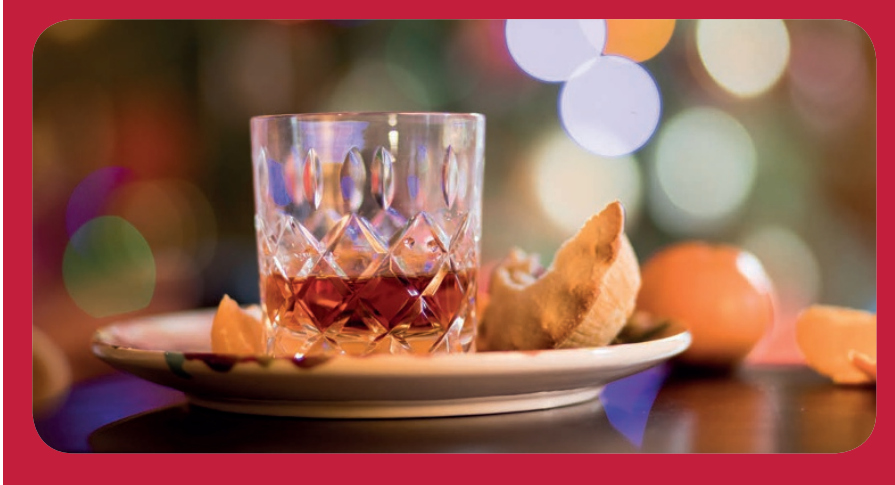

support of their product, proposing moderation and claiming that it was actually possible to 'just have a glass or two every now and then' and that 'bottomless brunches are not a wise choice every weekend'.

Producers of other luxury items have taken steps to counter any future claims that their products are harmful to oral health and have released many of these in time for the Christmas period. Galisker Distillery have released a fluoridated single malt whisky that they promise will not harm the drinker's teeth; UMunch Food Corporation have created a genetically modified range of nuts that are easier to chew and will not get stuck in your teeth; and Daisy Farm Foods have produced a turkey that has been pre-basted with toothpaste.

Whilst governing health bodies have lauded the innovation, food critics have not been so generous with praise. Tarquin BootheChewington of The Daily Spectator, commenting on the products, stated 'it is inedible slop that I wouldn't feed to my worst enemy'. 